\title{
Mammographic density and risk of breast cancer by tumor characteristics: a case- control study
}

Kavitha Krishnan ${ }^{1}$, Laura Baglietto 1,2,3, ${ }^{1}$ Jennifer Stone ${ }^{1,5}$, Catriona McLean ${ }^{6}$, Melissa C. Southey ${ }^{7}$, Dallas R. English ${ }^{1,2}$, Graham G. Giles ${ }^{1,2,8}$ and John L. Hopper ${ }^{1,9,10^{*}}$

\begin{abstract}
Background: In a previous paper, we had assumed that the risk of screen-detected breast cancer mostly reflects inherent risk, and the risk of whether a breast cancer is interval versus screen-detected mostly reflects risk of masking. We found that inherent risk was predicted by body mass index (BMI) and dense area (DA) or percent dense area (PDA), but not by non-dense area (NDA). Masking, however, was best predicted by PDA but not BMI. In this study, we aimed to investigate if these associations vary by tumor characteristics and mode of detection.

Methods: We conducted a case-control study nested within the Melbourne Collaborative Cohort Study of 244 screendetected cases matched to 700 controls and 148 interval cases matched to 446 controls. DA, NDA and PDA were measured using the Cumulus software. Tumor characteristics included size, grade, lymph node involvement, and ER, PR, and HER2 status. Conditional and unconditional logistic regression were applied as appropriate to estimate the Odds per Adjusted Standard Deviation (OPERA) adjusted for age and BMI, allowing the association with BMI to be a function of age at diagnosis.

Results: For screen-detected cancer, both DA and PDA were associated to an increased risk of tumors of large size (OPERA 1.6) and positive lymph node involvement (OPERA 1.8); no association was observed for BMI and NDA. For risk of interval versus screen-detected breast cancer, the association with risk for any of the three mammographic measures did not vary by tumor characteristics; an association was observed for BMI for positive lymph nodes (OPERA 0.6). No associations were observed for tumor grade and ER, PR and HER2 status of tumor.

Conclusions: Both DA and PDA were predictors of inherent risk of larger breast tumors and positive nodal status, whereas for each of the three mammographic density measures the association with risk of masking did not vary by tumor characteristics. This might raise the hypothesis that the risk of breast tumours with poorer prognosis, such as larger and node positive tumours, is intrinsically associated with increased mammographic density and not through delay of diagnosis due to masking.
\end{abstract}

Keywords: Mammographic density, Breast cancer, Detection mode, Tumor characteristics

\footnotetext{
* Correspondence: j.hopper@unimelb.edu.au

${ }^{1}$ Centre for Epidemiology and Biostatistics, Melbourne School of Population and Global Health, University of Melbourne, Level 3, 207 Bouverie Street, Carlton, VIC 3053, Australia

${ }^{9}$ Seoul Department of Epidemiology, School of Public Health, Seoul National University, Seoul, South Korea

Full list of author information is available at the end of the article
} International License (http://creativecommons.org/licenses/by/4.0/), which permits unrestricted use, distribution, and reproduction in any medium, provided you give appropriate credit to the original author(s) and the source, provide a link to the Creative Commons license, and indicate if changes were made. The Creative Commons Public Domain Dedication waiver (http://creativecommons.org/publicdomain/zero/1.0/) applies to the data made available in this article, unless otherwise stated. 


\section{Background}

Mammographic density (MD) is a risk factor for breast cancer $[1-5]$ and is also known to play a role in the masking of the tumor $[1,2,5]$. What is unclear is whether the influences of $\mathrm{MD}$ on inherent risk and masking vary by tumor characteristics. Knowledge on this might aid to understand the aetiology of breast cancer. Specifically, understanding if the dense tissues of the breast give rise to breast tumors of a specific kind might aid in understanding the biological mechanisms involved in the development of breast tumors. Understanding if masking varies by tumor characteristics might highlight the difference in the biology of the various tumors.

In a previous paper [6], we postulated that the risk of screen-detected breast cancer is mostly influenced by inherent risk, while risk of interval breast cancer is due to a combination of inherent risk and risk of masking. Therefore, given a woman participating in a screening program is diagnosed with breast cancer, the factors associated to the likelihood of having a screen-detected versus an interval cancer will mostly be those that influence risk of masking. We reported in the paper that inherent risk was predicted by body mass index (BMI) and dense area (DA) or percent dense area (PDA), but not by non-dense area (NDA), whereas masking was best predicted by PDA but not BMI [6].

Very few studies have analysed the association between MD and risk of breast cancer by tumor characteristics, separately for each detection mode [7-10]. Of these one study did not adjust for BMI [9], the rest did not allow for the association between BMI and risk to vary by age $[7,8,10]$ and none of them had investigated the concurrent associations of dense area (DA), percent dense area (PDA) and non-dense area (NDA).

For screen-detected cancer, studies have observed that higher density was associated with increased risk of larger tumors [7, 10] and nodal involvement [7] after adjusting for BMI. Results for interval cancer are more varied. One study observed a negative association between density and histologic grade, differentiation and mitotic index after adjusting for BMI but there was no statistically significant difference in the risk estimates between screen-detected and interval cases [10]. This might not be surprising as $66 \%$ of the interval cases were true interval cases thus, the risk of interval cancer would most likely reflect inherent risk similar to risk of screendetected cancer as postulated in our paper. Another study had combined interval cases with clinically detected cases (i.e. women with breast symptoms referred to for mammography) and reported density to be positively associated for oestrogen (ER)- and triple-negative tumors [8] and larger tumors [7] after adjusting for BMI.

Here we have used the same case-control study nested within the Melbourne Collaborative Cohort Study (MCCS) analysed before [6], to investigate if the association between DA, PDA and NDA and inherent risk of breast cancer, and the risk of masking vary by tumor characteristics, specifically size, grade, lymph node involvement, and ER, progesterone (PR), and human epidermal growth factor receptor 2 (HER2) status.

\section{Methods}

The MCCS is a prospective cohort study, which started recruiting participants from the Melbourne metropolitan area between 1990 and 1994. At study entry there were 41,514 participants (including 24,469 women) aged between 27 and 76 years. A nested case-control study was designed based on the subset of MCCS women who had been identified to have attended BreastScreen Victoria, a population-based screening program, through a record linkage conducted in 2009 (20,444 women). Cases were women who subsequently had a first diagnosis of invasive adenocarcinoma of the breast (International Classification of Diseases for Oncology codes C50.0-C50.9). Four controls were matched to each case by year of birth, year of entry into the MCCS and country of origin. The mammogram with craniocaudal view and closest to study entry was chosen for measurement. Screendetected cases were identified at BreastScreen Victoria. Cases diagnosed within 2 years of a negative screen at BreastScreen Victoria were defined as interval cases. There were 244 screen-detected cases matched to 700 controls and 148 interval cases matched to 446 controls. Further details about the nested case-control study have been published elsewhere $[6,11,12]$.

\section{Tumor characteristics}

The Victorian Cancer Registry (VCR) reviewed the pathology reports and classified the cancers according to tumor size, tumor grade, lymph node involvement, and ER, PR, and HER2 status. The original diagnostic tumor slides were retrieved for $85 \%$ of the cases from pathology laboratories and reviewed by a single pathologist $(C$. McLean) who assessed ER, PR, and HER2 status using immunohistochemistry techniques [13]. ER and PR tumors were categorized as positive if $\geq 1 \%$ of the nuclei were stained and/or the intensity of staining was weak, moderate, or strong and negative otherwise; HER2 tumors were categorized as positive if $>10 \%$ of the nuclei were stained and the intensity of staining was weak, moderate, or strong and negative otherwise. The agreements between the ER, PR, and HER2 status assessed by immunohistochemistry and the records held by the VCR were $91 \%, 70 \%$, and $72 \%$, respectively (for $\mathrm{ER}, \mathrm{K}=0.56$, $P<0.0001$; for PR, $\kappa=0.30, P<0.0001$; for HER2, $\kappa=$ $0.32, P<0.0001)$. Given the good agreement between the ER, PR, and HER2 data, when archival tumor tissue was 
not available, ER, PR, and HER2 status was assigned according to the histopathology reports held at the VCR.

\section{Statistical analyses}

Associations between the mammographic measures and risk were estimated in terms of odds per adjusted standard deviation (OPERA) according to models with different combinations of the variables, DA, PDA, NDA and BMI, as mentioned in our previous publication [6]. Further details about OPERA have been published elsewhere [14-16].

Firstly, by applying the Box-Cox method for transforming variables to the mammographic measures of the control group, DA, PDA and NDA were transformed to $\left(\mathrm{DA}^{0.2}-1\right) / 0.2$, $\left(\mathrm{PDA}^{0.2}-1\right) / 0.2$ and $\left(\mathrm{NDA}^{0.5}-1\right) / 0.5$, respectively. Linear regression was applied on each transformed mammographic measure, adjusting for age at mammogram, BMI (standardized according to the controls) and all the matching variables, and the residuals were standardized to have zero mean and unit variance. Conditional logistic regression of case-control status was then applied separately for screen-detected and interval cancers and for each tumour characteristic. The typespecific OPERA estimates were obtained by fitting an interaction term between the standardised residuals and a set-specific variable equal to the tumour type of the matching case. Heterogeneity by tumor characteristics was assessed using likelihood ratio test. Age at mammogram was fitted as a potential confounder.

For the models that included BMI measured at the MCCS study entry, we fitted an interaction between BMI (standardized based on the controls) and reference age (age at diagnosis for the case and for her matched controls) and its significance was assessed using the likelihood ratio test. We have reported the risk estimates for BMI at ages 50 and 70 to show the predicted risks corresponding to the pre- and postmenopausal age groups.

For the analyses of interval versus a screen-detected breast cancers, unconditional logistic regression was applied only to cases adjusted for age at mammogram. Association between BMI and risk of interval versus a screen-detected breast cancer did not depended on age at diagnosis.

The Bayesian information criterion (BIC) and the area under the receiver operating characteristic curve (AUC) were used to test for relative goodness of fit. Differences between AUCs were tested using the De Long's tests [17].

Sensitivity analyses were conducted in which we further adjusted for potential confounders: BMI at age 1821 years; age at menarche; parity and lactation; menopausal status; HRT use; OC use; alcohol consumption and energy intake; and the matching variables (country of birth, year of birth, year of cohort entry and reference age) using unconditional logistic regression. We further adjusted for family history of breast cancer. A sensitivity analysis was also conducted by excluding cases diagnosed within 2 years from the mammogram, and their matching controls.

A more detailed explanation of the method used to derive OPERA has been given in our previous publication [6]

Statistical analyses were performed using Stata 12.1 (Stata Corporation, College Station, TX). Two-sided $P<$ 0.05 was considered to be nominally statistically significant.

\section{Results}

As shown in Table 1, screen-detected cases were on average about 2 to 3 years older than interval cases at diagnosis (65 years vs 62 years, $P<0.001$ ), at study entry when covariates were measured ( 56 years vs 54 years, $P$ $=0.01$ ), and at the mammogram closest to study entry (59 years vs 57 years, $P<0.01$ ). Interval cases had on average greater DA and PDA and lesser total breast area and NDA than screen-detected cases $(P<0.01)$. There was no significant difference in BMI and all the other confounders except for menopausal status and alcohol consumption between the two types of cases. Within the screen-detected cases there were a higher percentage of menopausal women $(P=0.02)$ and lower percentage of alcohol consumers $(P<0.01)$ at cohort entry than the interval cases.

ER, PR and HER2 status was known for 95\%, 94\% and 93\% of the cases, respectively. Within the cases with known ER, PR or HER2 status, 282 (76\%) were ER+, 183 (50\%) were PR+, and 114 (31\%) were HER2+. Grade was known for $94 \%$ of the cases, which included $86(23 \%)$ well differentiated, 156 (42\%) moderately differentiated, and 126 (34\%) poorly differentiated tumors. Lymph node involvement was known for $93 \%$ of the cases of whom 104 (28\%) were node positive. Size of the tumor was known for $97 \%$ of the cases for which 101 (26\%) were $<1 \mathrm{~cm}, 167(44 \%)$ were between 1 to $2 \mathrm{~cm}$ and 114 (30\%) were $\geq 2 \mathrm{~cm}$.

Interval cases had more tumors with features predictive of poorer prognosis than screen-detected cases; ER( $30 \%$ vs $18 \%, P<0.01)$, PR- $(54 \%$ vs $43 \%, P=0.02)$, poorly differentiated tumors $(41 \%$ vs $27 \%, P<0.01)$, positive nodal status $(44 \%$ vs $16 \%, P<0.001)$ and larger tumor size, $\geq 2 \mathrm{~cm}$ ( $44 \%$ vs $20 \%, P<0.001)$.

Table 2 shows that both DA and PDA were positively associated with risk of larger breast tumors with an increase in risk of about $80 \%$ and $110 \%$ for tumors of size $2 \mathrm{~cm}$ and greater, respectively, per adjusted SD under all models (all test for heterogeneity by tumour size, $p<$ 0.01 ); the risk was significant but lower for tumors of size 1-2 $\mathrm{cm}$ and not significant for smaller tumours of size lesser than $1 \mathrm{~cm}$. DA and PDA also were positively 
Table 1 Characteristics of study participants

\begin{tabular}{|c|c|c|c|c|}
\hline & $\begin{array}{l}\text { Screen-detected cases } \\
(N=244)\end{array}$ & $\begin{array}{l}\text { Controls } \\
(N=700)\end{array}$ & $\begin{array}{l}\text { Interval cases } \\
(N=148)\end{array}$ & $\begin{array}{l}\text { Controls } \\
(N=446) \\
\text { Mean (SD) }\end{array}$ \\
\hline & Mean (SD) & Mean (SD) & Mean (SD) & \\
\hline Age at baseline, years & $56(8)$ & $56(8)$ & $54(8)$ & $54(8)$ \\
\hline Age at mammogram, years & $59(7)$ & $59(7)$ & $57(7)$ & $57(7)$ \\
\hline Age at diagnosis, years & $65(7)$ & & $62(7)$ & \\
\hline Time between age at mammogram and reference age, years & $6(3)$ & $6(3)$ & $5(3)$ & $5(4)$ \\
\hline Total energy intake, MJ/day & $8.4(2.9)$ & $8.6(3.5)$ & $8.7(3.2)$ & $8.7(3.1)$ \\
\hline \multicolumn{5}{|l|}{$\mathrm{BMl}, \mathrm{kg} / \mathrm{m} 2$} \\
\hline All women & $27.5(4.9)$ & $26.7(4.9)$ & $26.7(5.3)$ & $26.5(4.8)$ \\
\hline Premenopausal & $27.2(5.7)$ & $26.2(5.0)$ & $25.9(4.9)$ & $26.1(4.6)$ \\
\hline Postmenopausal & $27.6(4.6)$ & $27.0(4.9)$ & $27.2(5.5)$ & $26.7(5.0)$ \\
\hline BMl at age $18-21$ years, $\mathrm{kg} / \mathrm{m} 2$ & $21.5(2.9)$ & $21.5(2.9)$ & $21.4(2.5)$ & $21.5(2.8)$ \\
\hline \multicolumn{5}{|l|}{ Breast } \\
\hline Total area, cm2 & $143.7(60.9)$ & $137.8(57.6)$ & $125.0(56.9)$ & $133.4(60.3)$ \\
\hline Non-dense area, cm2 & $124.2(62.1)$ & $120.9(58.8)$ & $96.5(55.6)$ & $115.3(60.6)$ \\
\hline Dense area, $\mathrm{cm} 2$ & $19.6(21.7)$ & $16.8(20.6)$ & $28.5(24.5)$ & $18.1(19.4)$ \\
\hline Percent mammographic density, $\%$ & $15.5(15.7)$ & $14.0(15.3)$ & $25.2(17.9)$ & $15.4(14.7)$ \\
\hline Country of birth & N (\%) & $N(\%)$ & $N(\%)$ & N (\%) \\
\hline Anglo Saxon/ Other & $204(84)$ & $583(83)$ & $123(83)$ & $371(83)$ \\
\hline Italy & $25(10)$ & $74(11)$ & $13(9)$ & $40(9)$ \\
\hline Greece & $15(6)$ & $43(6)$ & $12(8)$ & $35(8)$ \\
\hline \multicolumn{5}{|l|}{ Age at menarche, years } \\
\hline$<12$ & $47(19)$ & $125(18)$ & $31(21)$ & $75(17)$ \\
\hline 12 & $52(21)$ & $145(21)$ & $25(17)$ & $86(19)$ \\
\hline 13 & $55(23)$ & $169(24)$ & $36(24)$ & $111(25)$ \\
\hline $14+$ & $88(36)$ & $261(37)$ & $56(38)$ & $174(39)$ \\
\hline \multicolumn{5}{|l|}{ Parity and lactation } \\
\hline Nulliparous & $38(16)$ & $84(12)$ & $25(17)$ & $62(14)$ \\
\hline Parous, never lactated & $10(4)$ & $61(9)$ & $12(8)$ & $34(8)$ \\
\hline Parous, lactated & $190(78)$ & $542(77)$ & $108(73)$ & $343(77)$ \\
\hline \multicolumn{5}{|l|}{ Menopausal status } \\
\hline Premenopausal & $69(28)$ & $195(28)$ & $59(40)$ & $170(38)$ \\
\hline Postmenopausal & $174(71)$ & $504(72)$ & $89(60)$ & $275(62)$ \\
\hline \multicolumn{5}{|l|}{ Hormone replacement therapy use } \\
\hline Never & $169(69)$ & $493(70)$ & $98(66)$ & $323(72)$ \\
\hline Ever & $74(30)$ & $205(29)$ & $49(33)$ & $122(27)$ \\
\hline \multicolumn{5}{|l|}{ Oral contraceptive use } \\
\hline Never & $93(38)$ & $283(40)$ & $58(39)$ & $157(35)$ \\
\hline Ever & $150(61)$ & $415(59)$ & $90(61)$ & $287(64)$ \\
\hline \multicolumn{5}{|l|}{ Alcohol consumption } \\
\hline Lifetime abstainers & $109(45)$ & $257(37)$ & $43(29)$ & $160(36)$ \\
\hline Ex-drinkers & $13(5)$ & $24(3)$ & $3(2)$ & $13(3)$ \\
\hline Low intake, 1-19 g/day & $97(40)$ & $337(48)$ & $78(53)$ & $223(50)$ \\
\hline Medium intake, 20-39 g/day & $19(8)$ & $61(9)$ & $20(14)$ & $38(9)$ \\
\hline High intake, $\geq 40 \mathrm{~g} /$ day & $6(2)$ & $21(3)$ & $4(3)$ & $12(3)$ \\
\hline
\end{tabular}


Table 1 Characteristics of study participants (Continued)

\begin{tabular}{|c|c|c|c|c|}
\hline & $\begin{array}{l}\text { Screen-detected cases } \\
(N=244) \\
\text { Mean (SD) }\end{array}$ & $\begin{array}{l}\text { Controls } \\
(N=700) \\
\text { Mean (SD) }\end{array}$ & $\begin{array}{l}\text { Interval cases } \\
(N=148) \\
\text { Mean (SD) }\end{array}$ & $\begin{array}{l}\text { Controls } \\
(N=446) \\
\text { Mean (SD) }\end{array}$ \\
\hline \multicolumn{5}{|l|}{ Family history of breast cancer ${ }^{a}$} \\
\hline No & $185(76)$ & $548(78)$ & $101(68)$ & $341(76)$ \\
\hline Yes & $38(16)$ & $77(11)$ & $30(20)$ & $43(10)$ \\
\hline \multicolumn{5}{|l|}{ ER } \\
\hline Positive & $188(77.0)$ & & $94(63.5)$ & \\
\hline Negative & $45(18.4)$ & & $45(30.4)$ & \\
\hline \multicolumn{5}{|l|}{$P R$} \\
\hline Positive & $126(51.6)$ & & $57(38.5)$ & \\
\hline Negative & $106(43.4)$ & & $80(54.1)$ & \\
\hline \multicolumn{5}{|l|}{ HER2 } \\
\hline Positive & $73(29.9)$ & & $41(27.7)$ & \\
\hline Negative & $153(62.7)$ & & $96(64.9)$ & \\
\hline \multicolumn{5}{|l|}{ Grade } \\
\hline Well differentiated & $62(25.4)$ & & $24(16.2)$ & \\
\hline Moderately differentiated & $104(42.6)$ & & $52(35.1)$ & \\
\hline Poorly differentiated & 65 (26.6) & & $61(41.2)$ & \\
\hline \multicolumn{5}{|l|}{ Size } \\
\hline$<1 \mathrm{~cm}$ & $76(31.1)$ & & $25(16.9)$ & \\
\hline $1-2 \mathrm{~cm}$ & $116(47.5)$ & & $51(34.5)$ & \\
\hline$\geq 2 \mathrm{~cm}$ & $49(20.1)$ & & $65(43.9)$ & \\
\hline \multicolumn{5}{|l|}{ Nodal Status } \\
\hline Positive & $39(16.0)$ & & $65(43.9)$ & \\
\hline Negative & $190(77.9)$ & & $71(48.0)$ & \\
\hline
\end{tabular}

Abbreviations: $B M I$ body mass index, $S D$ standard deviation

${ }^{a}$ Family history of breast cancer is defined as having any relative with breast cancer

associated with positive lymph nodes with risk gradients of about $90 \%$ and $110 \%$, respectively, per adjusted SD under all models; whereas the risk associated to negative lymph nodes was lower (all test for heterogeneity by nodal status, $\mathrm{p}<0.01)$. The model including only PDA gave the best fit when analysing tumor size $(B I C=1110$, $\mathrm{AUC}=0.68)$ and lymph node involvement $(\mathrm{BIC}=1041$, $\mathrm{AUC}=0.68$ ). BMI and NDA were not associated with the size of the tumor and nodal involvement under any model. None of the three mammographic measures and BMI were associated with the other tumor characteristics.

Similar to risk of breast cancer overall, DA and PDA were positively associated with risk of screen-detected breast tumors of large size and positive lymph node involvement (Table 3). But unlike risk of breast cancer overall, models including either DA or PDA gave the best fit when analysing tumor size and lymph node involvement. For tumor size, the model including only PDA had $\mathrm{BIC}=647$ and the model including only DA had a BIC $=648$ and both the models had a AUC $=0.64$. For nodal status, the model including only PDA had
$\mathrm{BIC}=611$ and $\mathrm{AUC}=0.63$ while the model including only DA had a $\mathrm{BIC}=612$ and $\mathrm{AUC}=0.64$. Both $\mathrm{MD}$ measures were associated with similar risk estimates; about $60 \%$ increase in risk of tumors of size $2 \mathrm{~cm}$ and greater and about $80 \%$ increase in risk of positive lymph nodes. When restricted to small tumors $(<2 \mathrm{~cm})$, the positive association between MD and positive nodal involvement remained (results not shown). BMI and NDA were not associated with the size of the tumor and nodal involvement under any model. None of the three mammographic measures and BMI were associated with the other tumor characteristics for screen-detected cancer.

The association between risk of interval cancer and DA, NDA and PDA did not vary by any of the tumor characteristics (Table 4). Higher BMI was associated with a decreased risk of negative lymph nodes at 50 years and increased risk of negative lymph nodes at 70 years.

None of the three mammographic measures were associated with risk of interval versus screen-detected breast cancer by any of the tumor characteristics (Table 5). BMI was negatively associated with risk of 


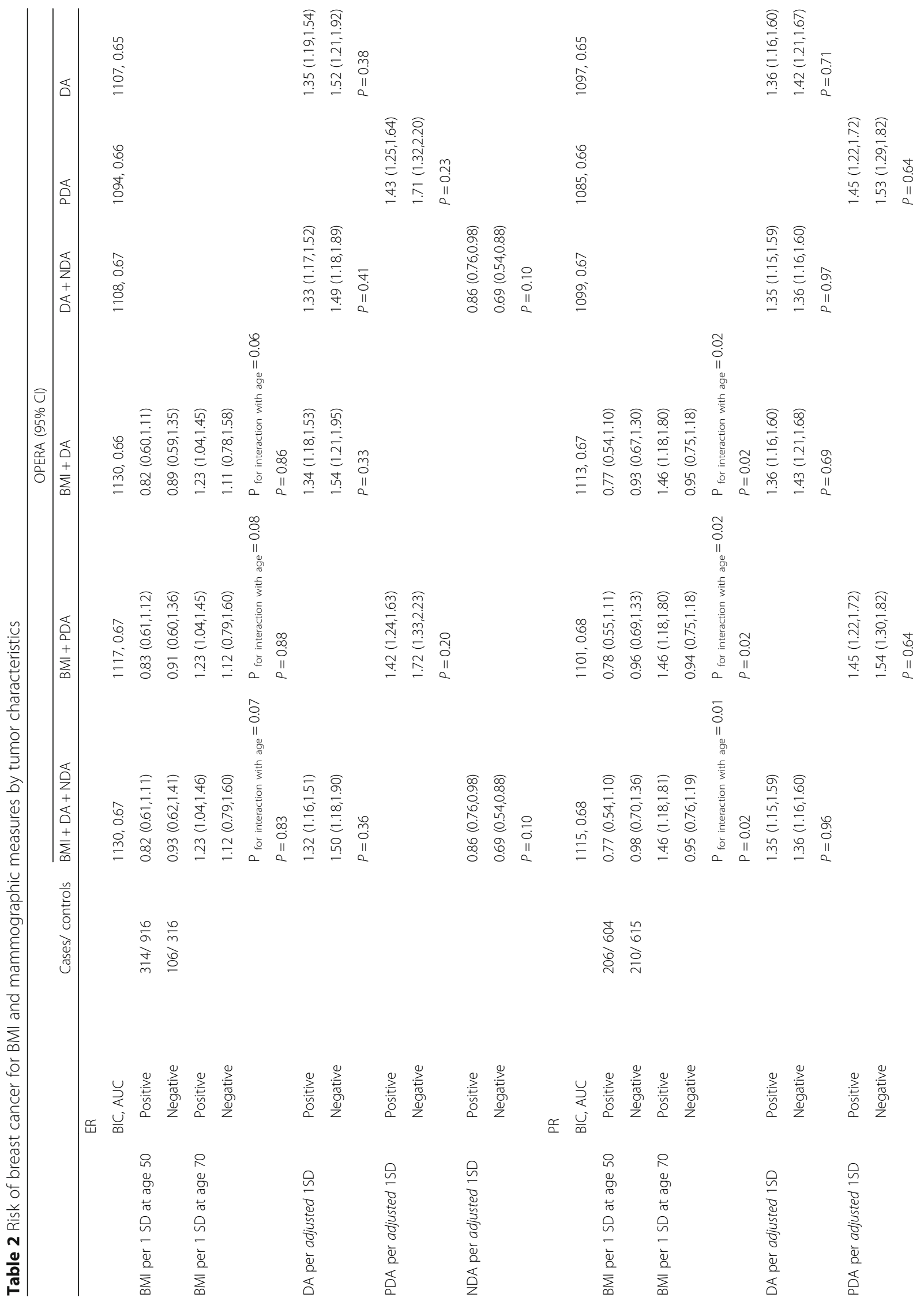




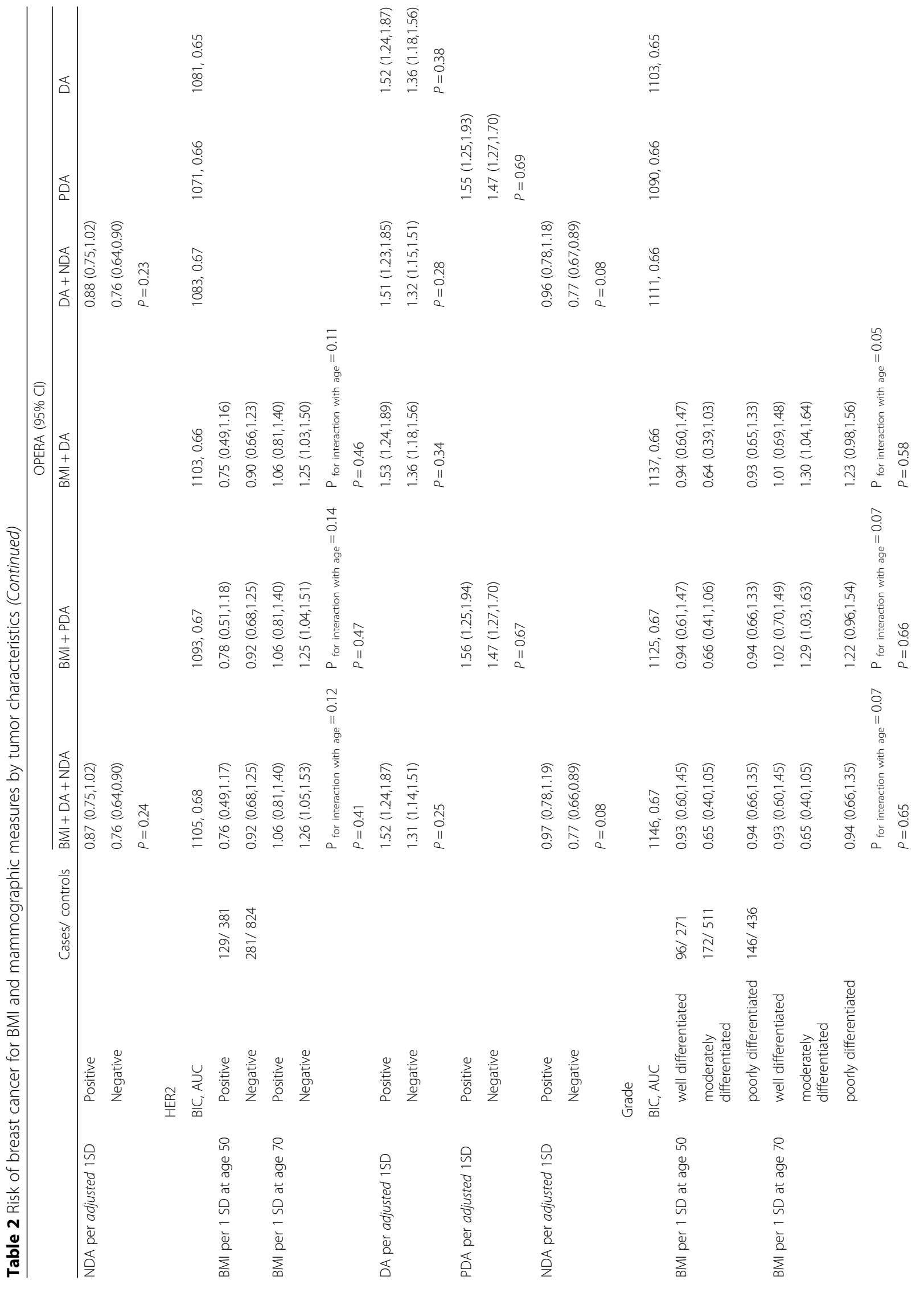




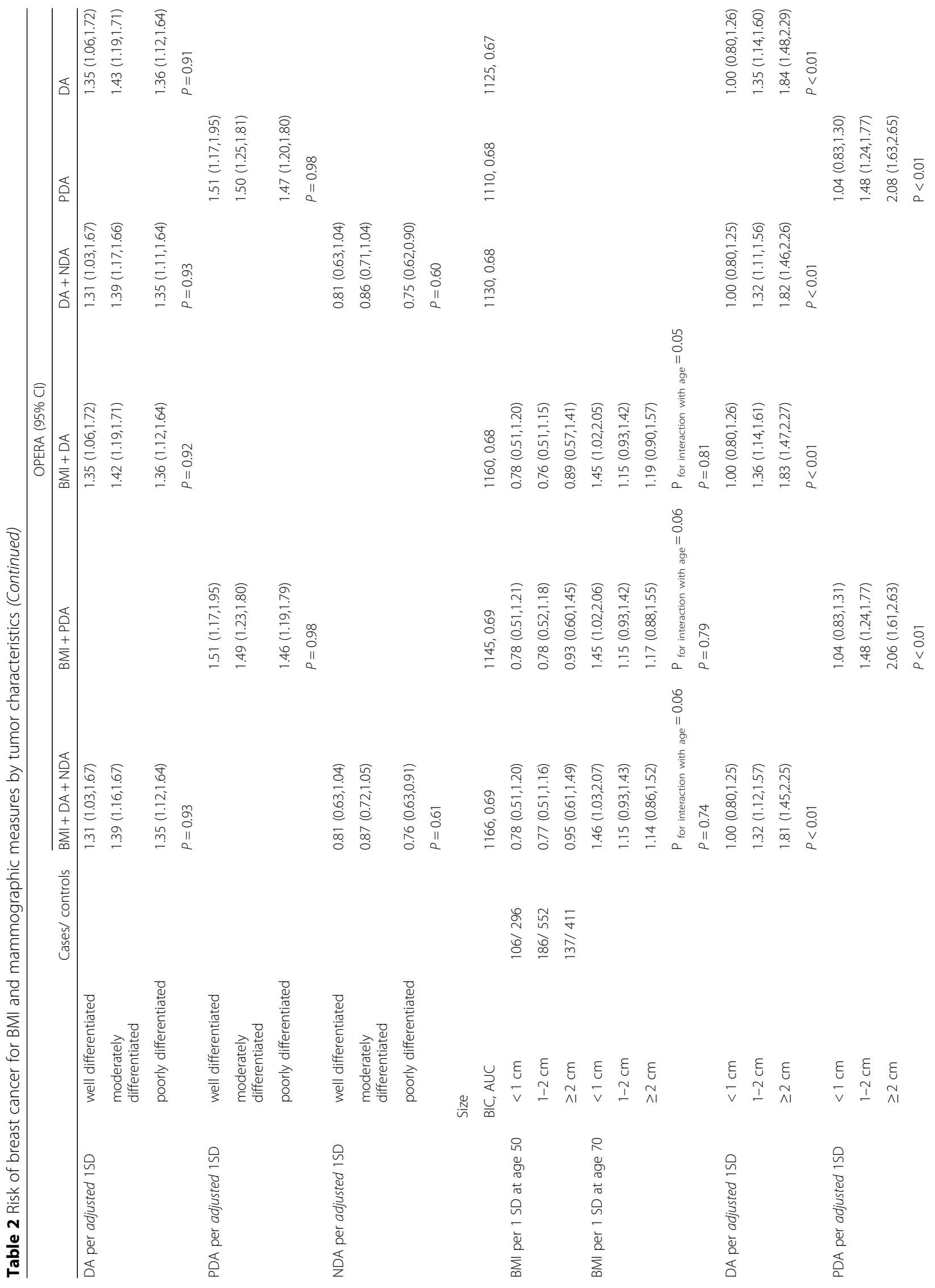


Krishnan et al. BMC Cancer (2017) 17:859

Page 9 of 23

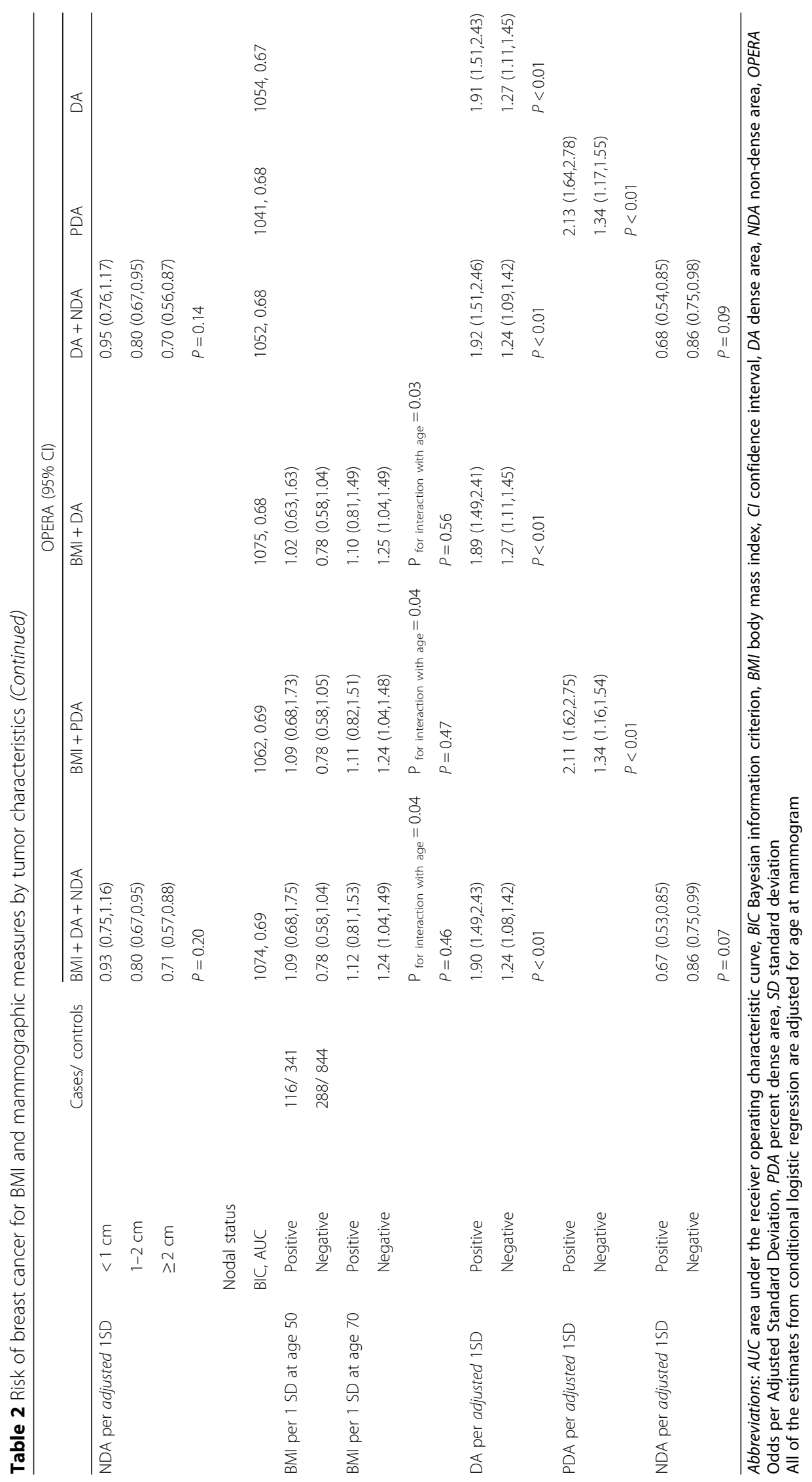




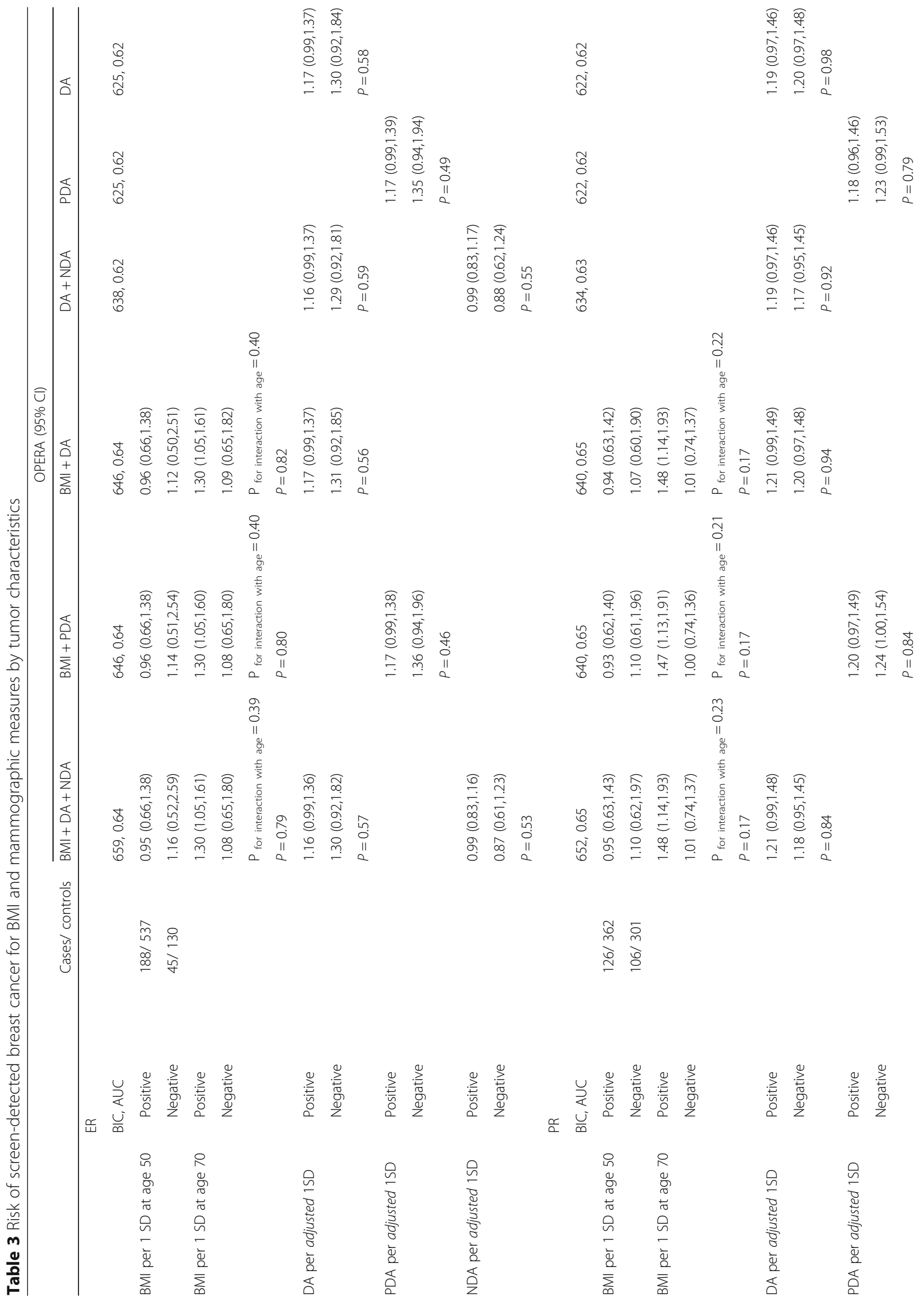




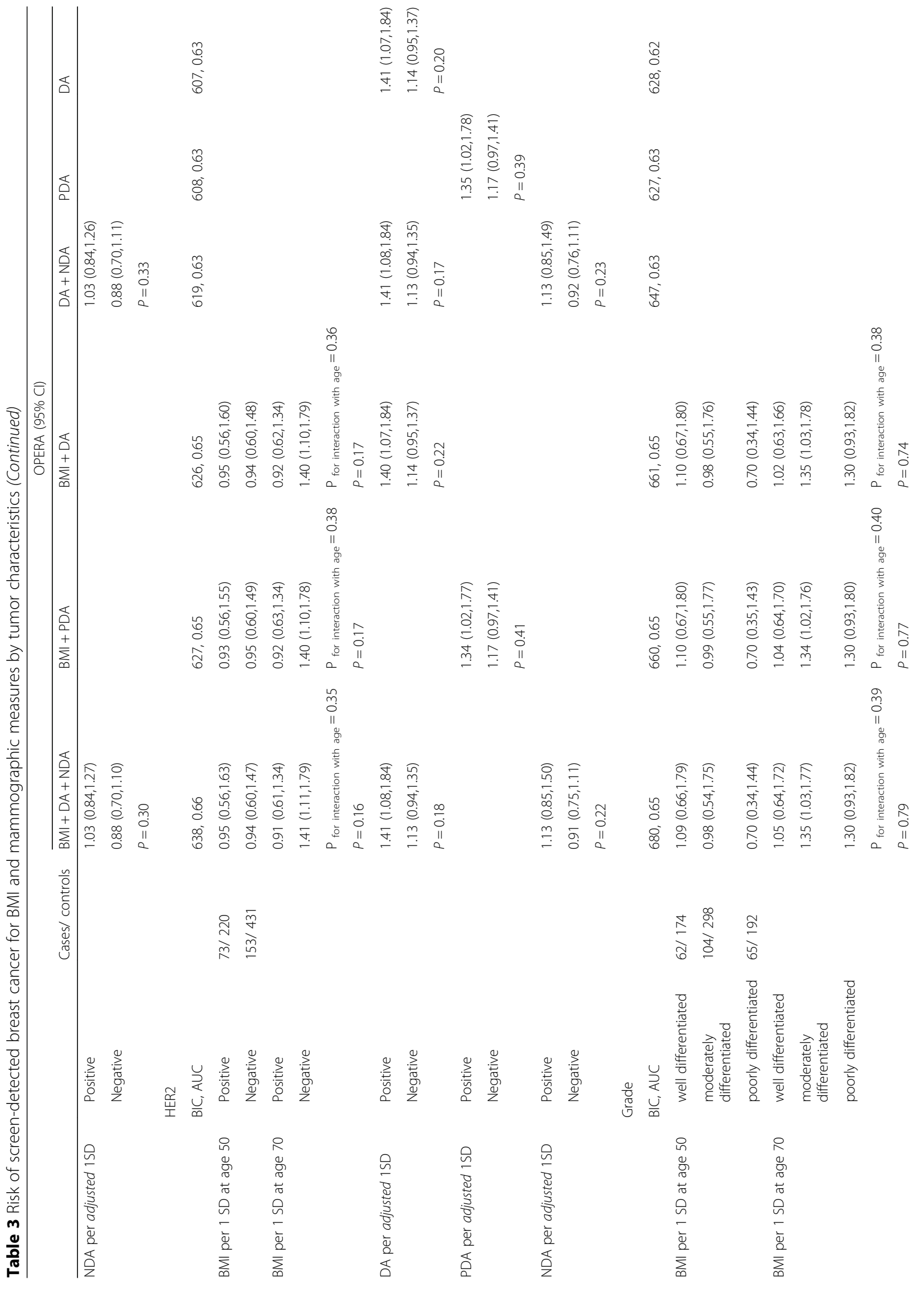




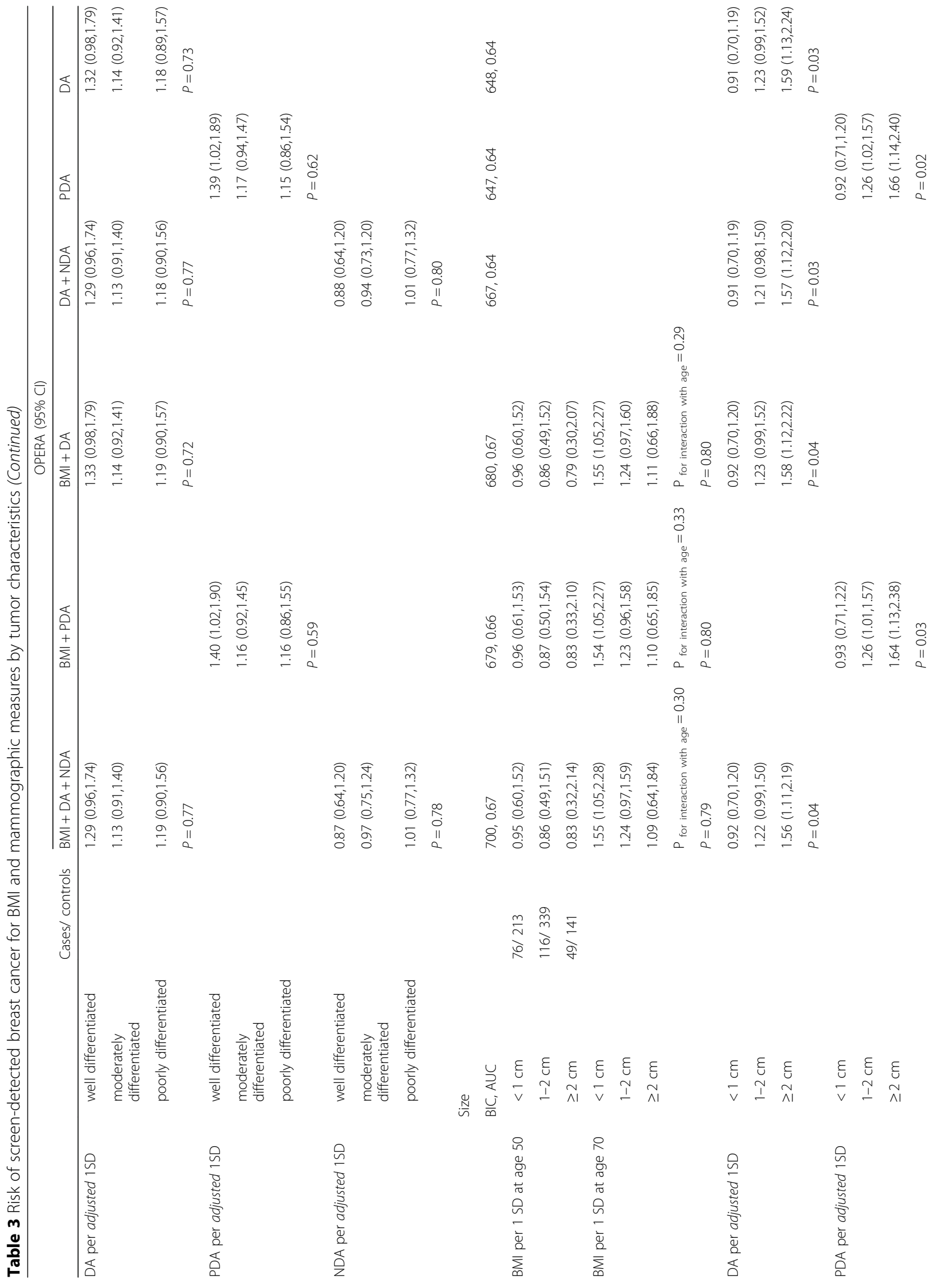


Krishnan et al. BMC Cancer (2017) 17:859

Page 13 of 23

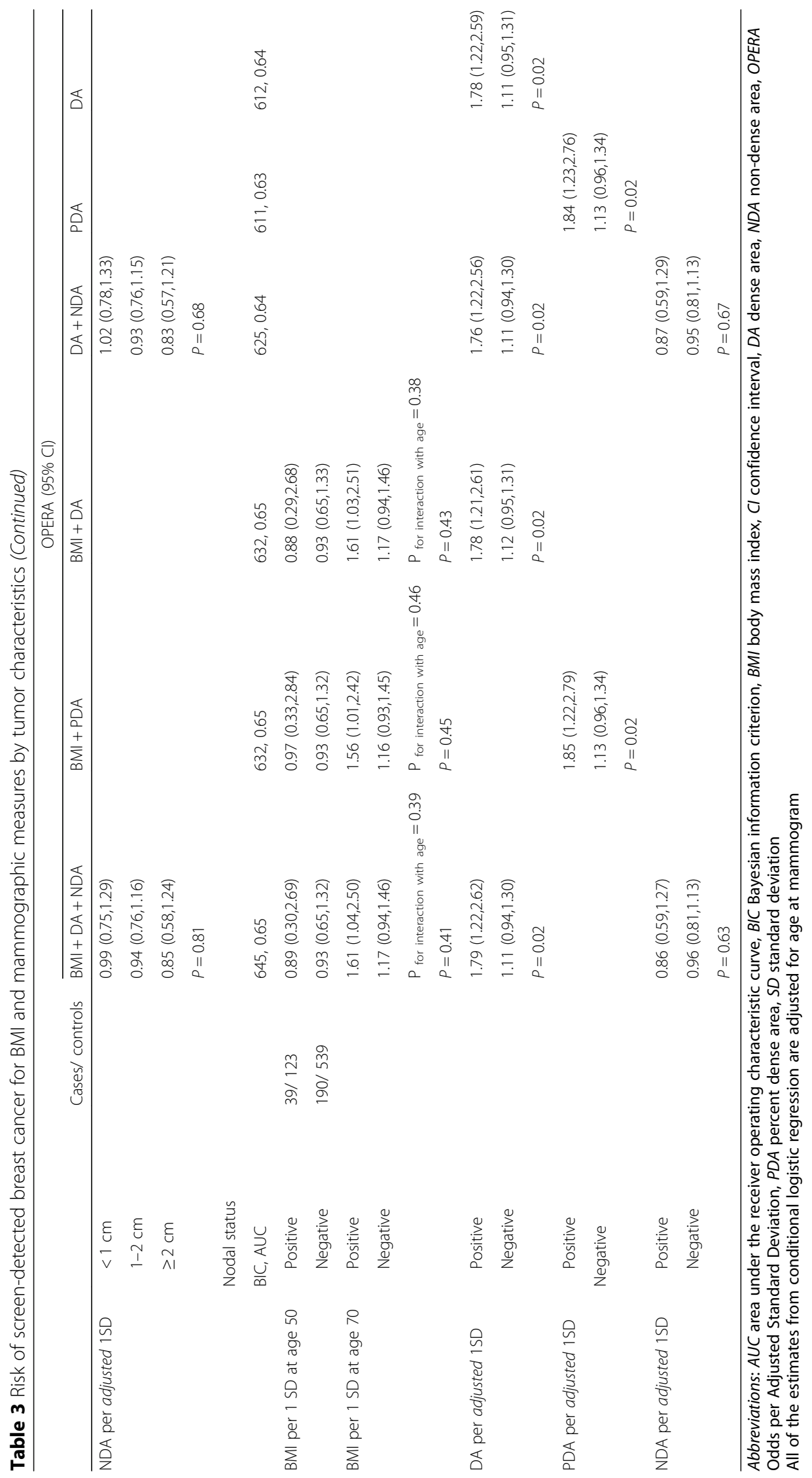




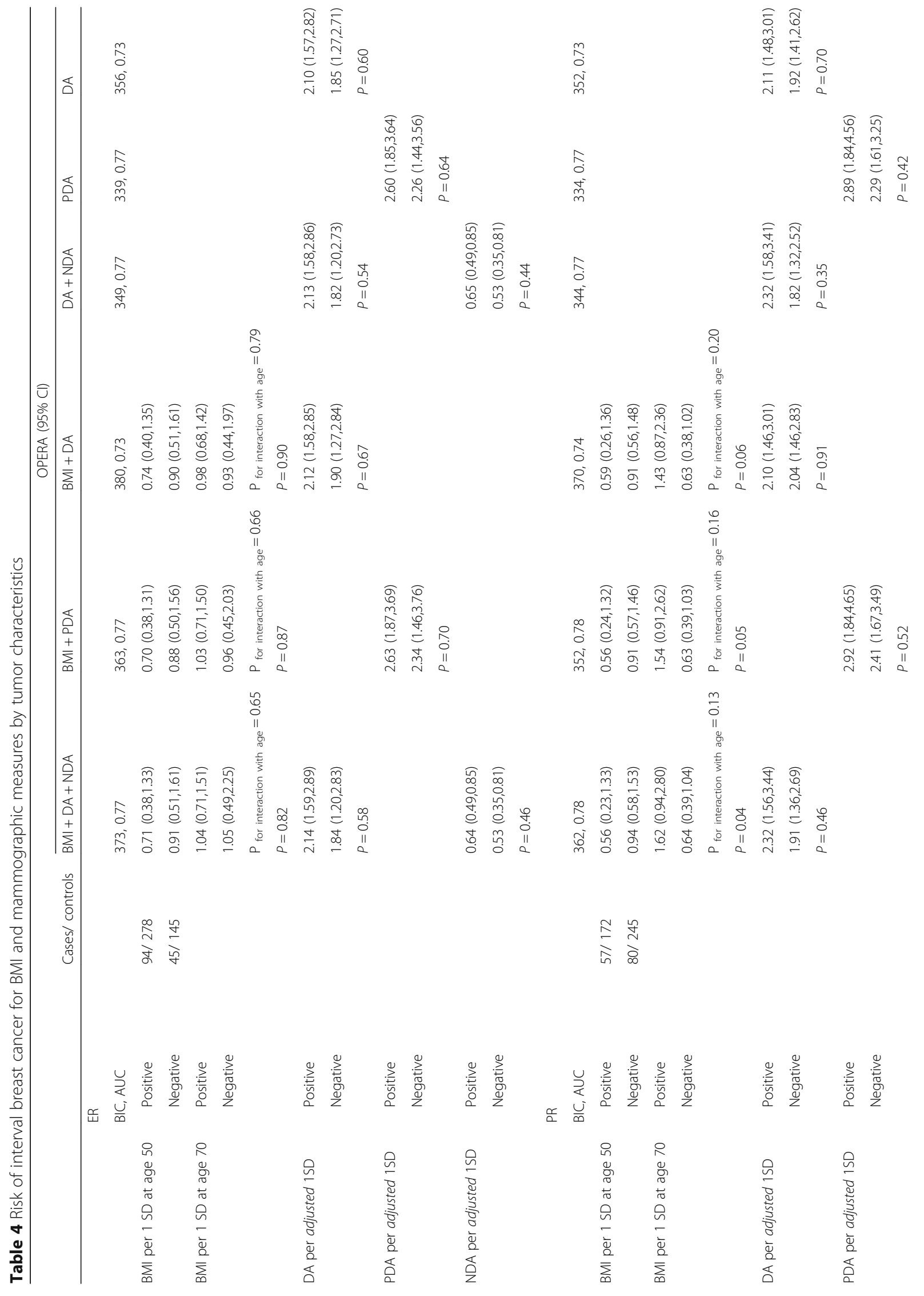




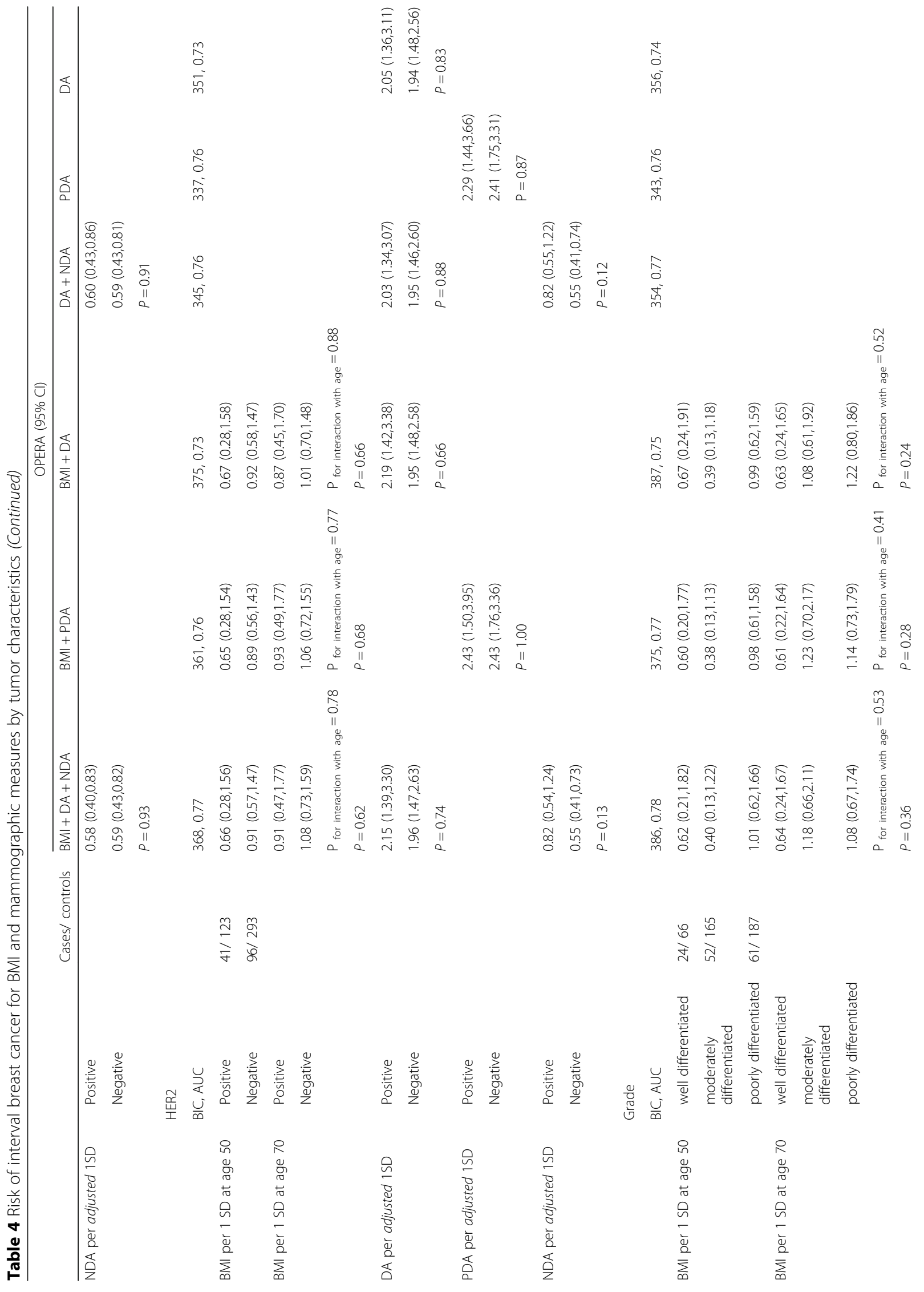




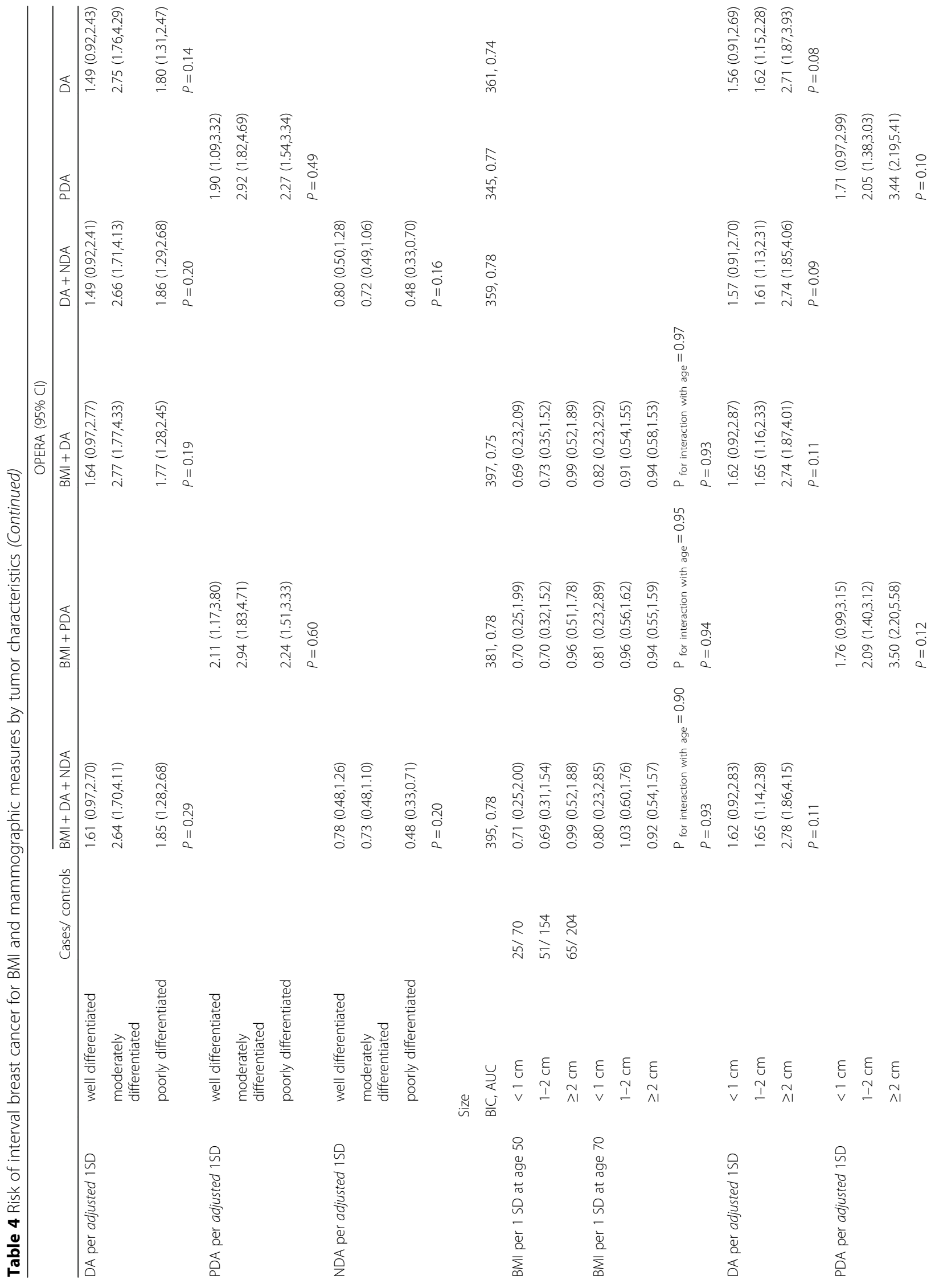




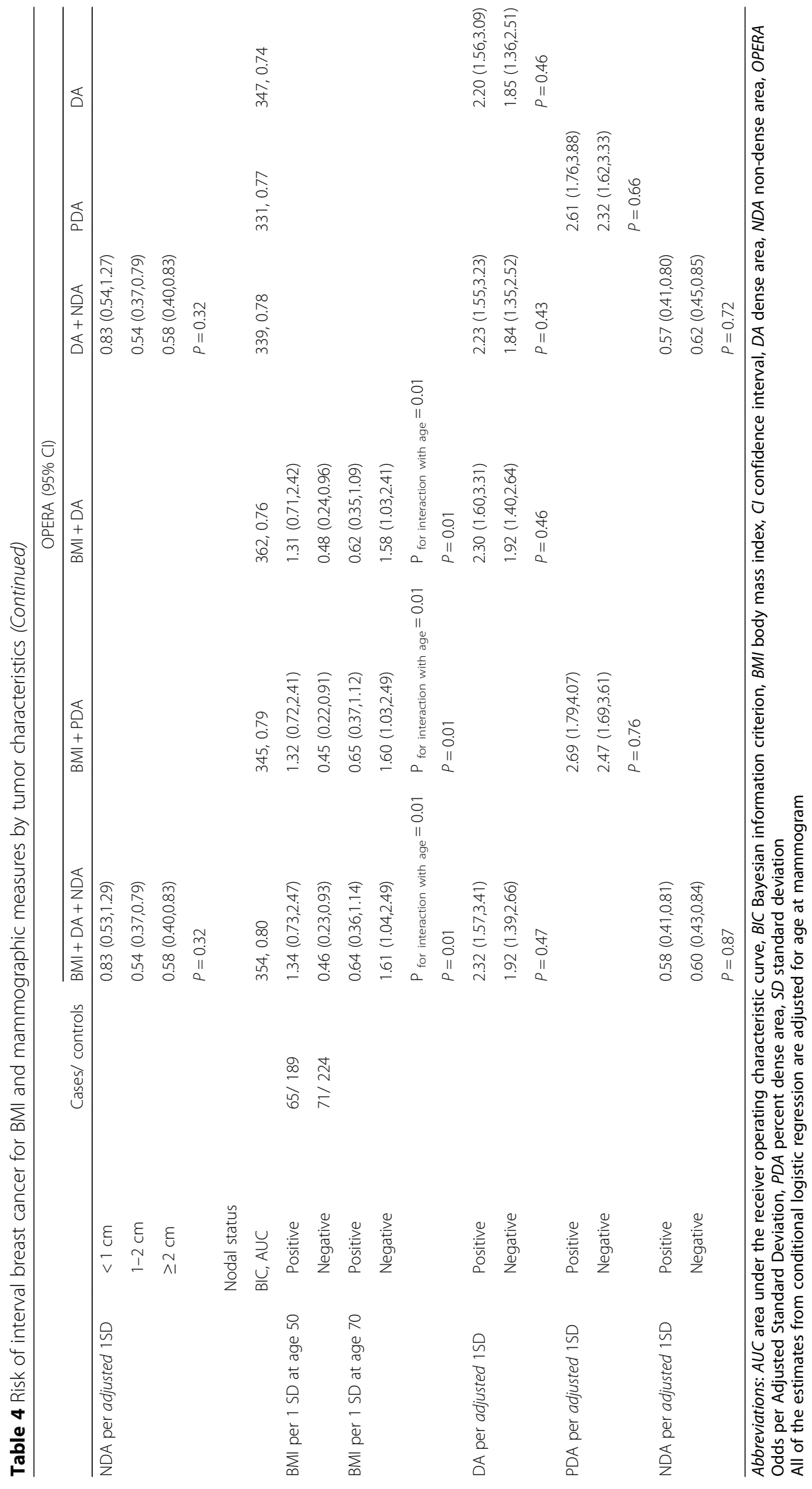




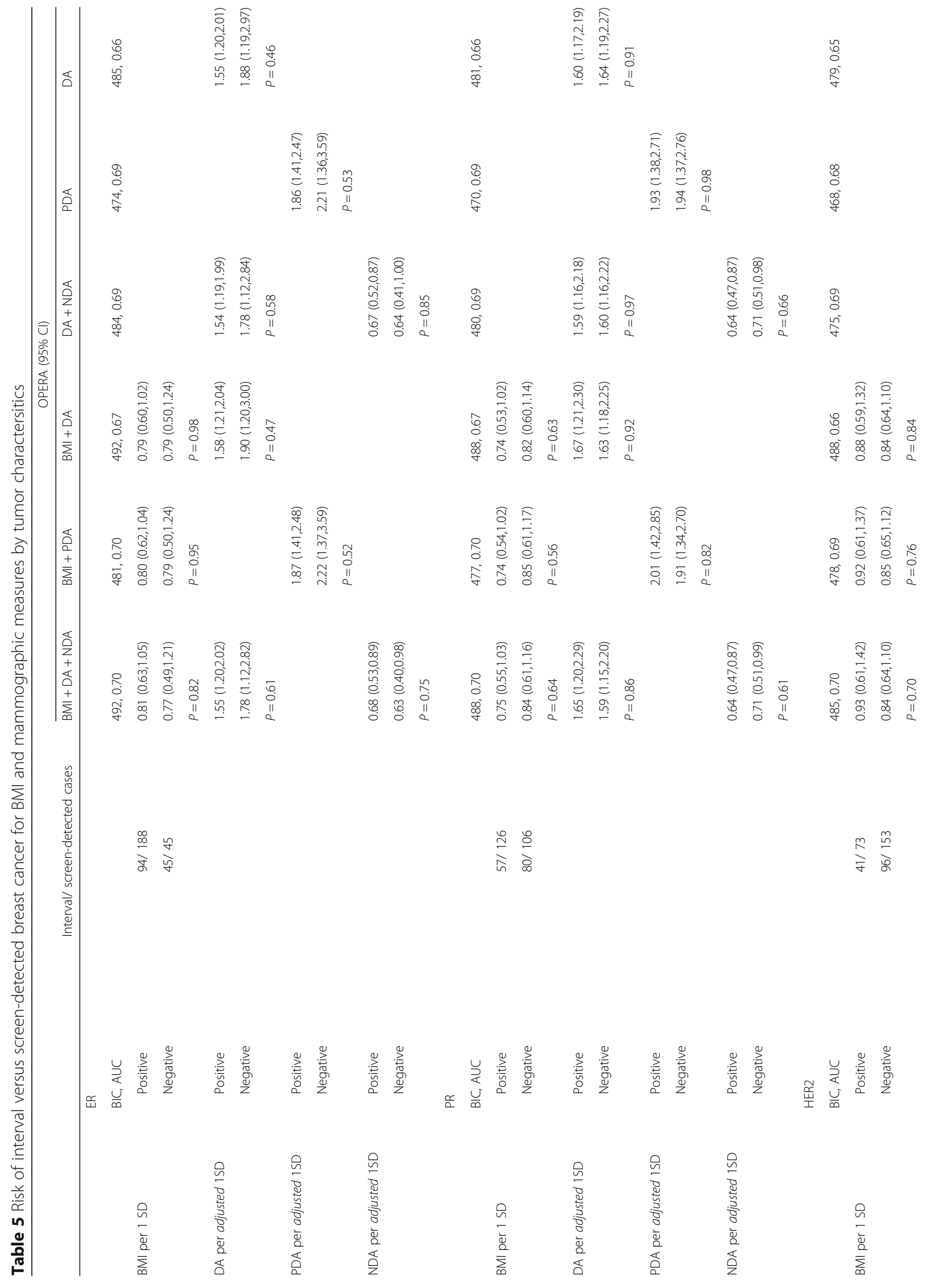


Krishnan et al. BMC Cancer (2017) 17:859

Page 19 of 23

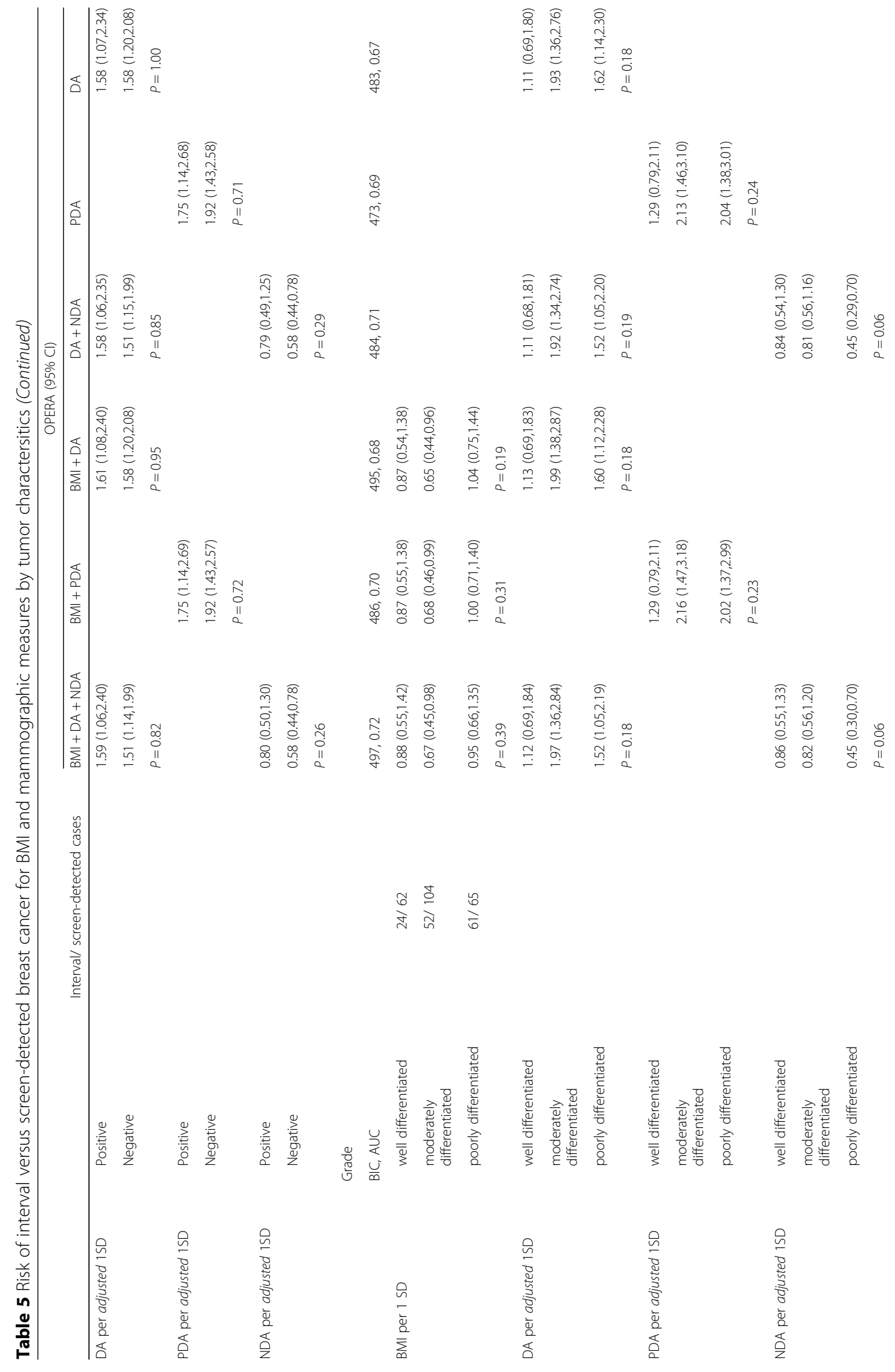




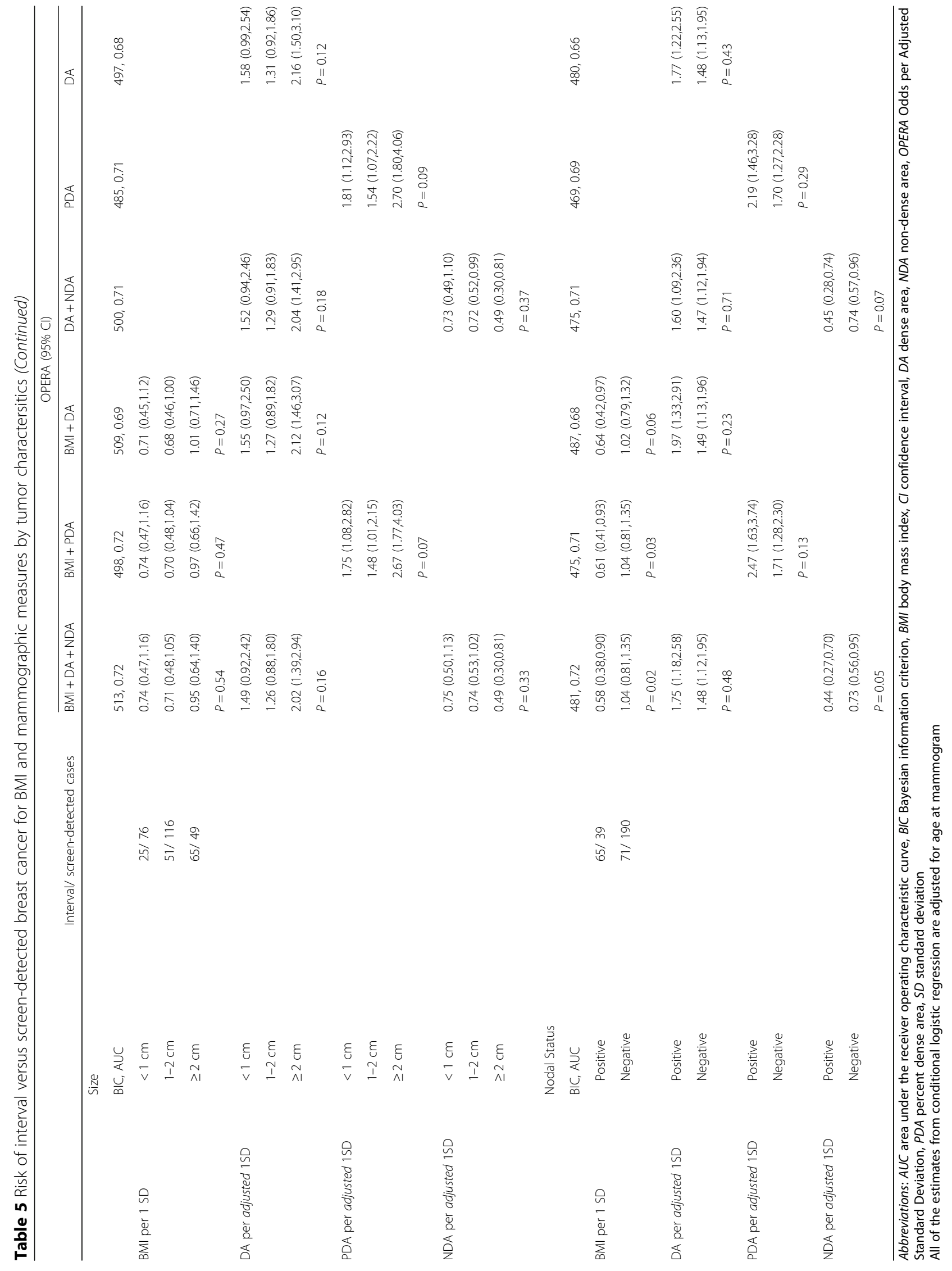


interval versus screen-detected cancer for tumors of 1 to $2 \mathrm{~cm}$ in size but not after adjusting for the mammographic measures. BMI was, however, associated with decreased risk of interval cancer with positive lymph nodes compared to screen-detected cancer, both significantly and marginally significantly after adjusting for the mammographic measures (all test for heterogeneity by nodal status, $p=0.02,0.03$ and 0.06 ).

The findings above were similar when we adjusted for all the confounders. No substantial differences in estimates were observed from the sensitivity analyses.

\section{Discussion}

As assumed in our previous paper [6], that risk of screen-detected cancers mostly reflects inherent cancer risk, and the predictors of interval versus screendetected disease mostly reflect predictors of masking, we found that both DA and PDA are positively associated with inherent risk of larger breast tumors and positive nodal involvement. Associations between DA, NDA and PDA, and risk of masking of tumors did not vary by tumor characteristics. None of the three mammographic measures were associated with differential nodal involvement for interval versus screen-detected cancer. However, BMI was associated with a decreased risk of positive nodal involvement for interval versus screendetected cancer.

Our results are similar to those of a large study consisting of six pooled datasets, which also found DA and PDA to be associated with increased risk of larger tumors, but found only PDA to be positively associated with positive nodal status [18]. Unlike our study, the pooled study [18] had also found DA to be positively associated with ER+ and PR+ tumors, and NDA to be negatively associated with the size of the tumor and HER2+. A meta-analysis [19], however, found no differential association between MD and risk by ER and HER2 status of tumors. The differences in the results could be due to the fact that the previous reports did not allow the relation between relative risk and BMI to depend on age.

Some studies analysing screen-detected breast cancer had also found MD to be associated with increased risk of larger tumors $[7,10]$ and positive nodal involvement [7], and none of them allowed the relation between risk and BMI to depend on age. Only one study, which did not adjust for BMI, found no association between MD and size of the tumor or nodal status for screen-detected breast cancer [9]. We had interpreted risk of screendetected breast cancer to be mainly representative of risk of developing a detectable breast tumor, assuming that the cases did not have a detectable tumor at prior mammograms. As mentioned in our previous paper [6], this assumption could be reasonable based on a review
[20] which found that within interval cases, which consists of true interval cases, false-negative cases (tumor is not identified at a mammogram due to reader error) and occult tumors (tumor is not identified at a mammogram due to high density), there was a lesser percentage of the latter two cases; false-negative cases (25-40\%) and occult tumors (8-12\%). Our findings, therefore, suggest there is a biological relationship between the amount of dense tissues in the breast and faster growth rate of the tumor. When restricted to small tumors $(<2 \mathrm{~cm})$, the positive association between MD and positive nodal involvement remained which could indicate that besides faster growth rate, there might be another biological mechanism that is involved between dense tissues and spreading of the tumor to the lymph nodes. Overall, this would support the indication that more frequent screening schedules should be offered to women with greater age- and BMI-adjusted MD.

We found no association between any of the mammographic measures and risk of interval breast cancer by tumor characteristics. Few studies had investigated risk by tumor characteristics separately for interval cancer. One study found greater MD to be associated with increased risk of ER+ interval cancer but it had not adjusted for BMI [9]. Another study found an inverse association between MD and grade of tumor for interval cancers, but it had only allowed the association between risk and BMI to be a constant. To our knowledge, none of the studies had reported on the association between BMI and risk of interval cancer by tumor characteristics after adjusting for the mammographic measures. However, our finding of BMI being associated with increased risk of interval cancer with positive lymph nodes at age 50 is consistent with earlier studies that had analysed cases overall $[21,22]$, while another study found no correlation between the number of lymph nodes affected and BMI [23]. None of these studies had allowed the association with BMI to vary by age and the mean age of their study participants was younger, between 47 to 50 years. As mentioned in our previous study [6], risk of interval cancer is more likely a combination of risk of developing the tumor and risk of masking, and also influenced by the rate of tumor growth. Consequently, the results for risk of interval cancer are difficult to interpret.

We found no association between all three mammographic measures and risk of interval versus screendetected cancer by tumor characteristics. A study which had further categorised interval cancer into true interval, false negatives, minimal-sign cancers and occult tumors also found no association between PDA and risk of each of the interval cancer category mentioned above compared with screen-detected cancer for the tumor phenotype, luminal A, luminal B, HER2 and triple-negative 
[24]. Another study, which had stratified by PDA (low versus high), found that for women with low PDA, interval cancers were more likely to be HER2+ and have positive nodal involvement compared with screen-detected cancers [25]. Both the studies, however, did not adjust for BMI $[24,25]$. Our results for BMI, however, needs to be confirmed by other studies as to our knowledge this is the first study to investigate the association between $\mathrm{BMI}$ and risk by tumor characteristic and taking into account the detection mode.

To our knowledge, our study is the first to estimate the differential risk of developing breast cancer and risk of masking by tumor characteristics through investigating the concurrent associations with all three mammographic measures, DA, NDA and PDA stratified by detection mode. BMI has been measured at cohort entry and we had realistically allowed the BMI association to vary by age since BMI is known to have differential associations on breast cancer risk; BMI is negatively associated with breast cancer risk for premenopausal women and positively associated with breast cancer risk for postmenopausal women [26]. A limitation of our study is the sample size, especially for small subgroups. Our ER, PR and HER2 status of tumors was measured by only one pathologist using immunohistochemistry method which might lead to non-differential misclassification of the status of the tumors and this most likely will attenuate the risk estimates towards null. Other limitations have been mentioned in our previous paper [6].

\section{Conclusions}

We found that both DA and PDA predicted inherent risk of larger breast tumors and positive nodal status. There was no differential risk of masking by tumor characteristics associated with DA, NDA and PDA. None of the three mammographic measures were associated with differential nodal involvement for interval versus screendetected cancer. Our finding suggest that the dense tissues of the breast play a role in faster growth rate of the tumor and in spreading of the tumor to the lymph nodes that would not be explained by delay of the diagnosis due to masking.

\section{Abbreviations \\ AUC: Area under the receiver operating characteristic curve; BIC: Bayesian information criterion; BMI: Body mass index; DA: Dense area; MCCS: Melbourne Collaborative Cohort Study; MD: Mammographic density; NDA: Non-dense area; OPERA: Odds per Adjusted Standard Deviation; PDA: Percent dense area; SD: Standard deviation; VCR: Victorian Cancer Registry}

\section{Acknowledgements}

We thank the Victorian Cancer Registry, BreastScreen Victoria, the Australian Mammographic Density Research Facility and Christopher Evans for reading the MCCS mammograms.

\section{Funding}

The MCCS is a research platform designed and maintained by Cancer Council Victoria. Recruitment to the MCCS was funded by Cancer Council of Victoria assisted by a grant in aid from VicHealth. Cancer Council Victoria continues to support MCCS maintenance and follow-up. This work was designed and supported by Cancer Council Victoria, assisted by grants from the Victorian Breast Cancer Research Consortium, the National Health and Medical Research Council (209,057 and 396,414), and the National Breast Cancer Foundation and by infrastructure (Australian Mammographic Density Research Facility) provided by the University of Melbourne. KK was supported by the John and Allan Gilmour Research Award and the May Stewart Bursary scholarships. JLH is a Senior Principal Research Fellow of the National Health and Medical Research Council and a Redmond Barry Distinguished Professor of the University of Melbourne. MCS is a Senior Research Fellow of the National Health and Medical Research Council. LB is supported by a Marie Curie International Incoming Fellowship within the 7th European Community Framework Programme.

\section{Availability of data and materials}

Melbourne Collaborative Cohort Study (MCCS) data may be accessed for scientific collaboration by application to the Management Committee. The policies and procedures governing access to and the use of MCCS data may be obtained from the PEDIGREE website (www.pedigree.org.au) along with application forms.

\section{Authors' contributions}

KK carried out the design of the nested case-control study, read the mammograms, performed the statistical analyses, interpreted the results and drafted the manuscript. LB was involved in the conception and design of the study, interpretation of results and helped to revise the manuscript. JS read the mammograms and helped to revise the manuscript. CM was involved in the design of the study and the acquisition of data. MCS was involved in the conception and design of the study and helped to revise the manuscript. DRE was involved in the conception and design of the study and helped to revise the manuscript. GGG was involved in the conception and design of the study and helped to revise the manuscript. JLH was involved in the conception and design of the study, supervised the statistical analyses, was involved in the interpretation of the results and helped to revise the manuscript. All authors read and approved the final manuscript.

\section{Ethics approval and consent to participate}

The Cancer Council Victoria's Human Research Ethics Committee approved the study protocol. Subjects gave written consent to participate and for the investigators to obtain access to their medical records.

\section{Consent for publication}

Not applicable

\section{Competing interests}

The authors declare that they have no competing interests.

\section{Publisher's Note}

Springer Nature remains neutral with regard to jurisdictional claims in published maps and institutional affiliations.

\section{Author details}

${ }^{1}$ Centre for Epidemiology and Biostatistics, Melbourne School of Population and Global Health, University of Melbourne, Level 3, 207 Bouverie Street, Carlton, VIC 3053, Australia. ${ }^{2}$ Cancer Epidemiology Centre, Cancer Council Victoria, Melbourne, Australia. ${ }^{3}$ Université Paris-Saclay, Univ. Paris-Sud, UVSQ, CESP, INSERM, Villejuif, France. ${ }^{4}$ Gustave Roussy, F-94805 Villejuif, France. ${ }^{5}$ Centre for Genetic Origins of Health and Disease, University of Western Australia, Perth, Australia. ${ }^{6}$ The Alfred Hospital, Melbourne, Australia. ${ }^{7}$ Genetic Epidemiology Laboratory, Department of Pathology, University of Melbourne, Melbourne, Australia. ${ }^{8}$ Department of Epidemiology and Preventive Medicine, Monash University, Melbourne, Australia. ${ }^{9}$ Seoul Department of Epidemiology, School of Public Health, Seoul National University, Seoul, South Korea. ${ }^{10}$ Institute of Health and Environment, Seoul National University, Seoul, South Korea. 
Received: 6 November 2016 Accepted: 4 December 2017

Published online: 16 December 2017

\section{References}

1. Wang AT, Vachon CM, Brandt KR, Ghosh K. Breast density and breast cancer risk: a practical review. Mayo Clin Proc. 2014;89:548-57.

2. McCormack VA, dos Santos Silva I. Breast density and parenchymal patterns as markers of breast cancer risk: a meta-analysis. Cancer epidemiology, biomarkers \& prevention: a publication of the American Association for Cancer Research, cosponsored by the American Society of Preventive Oncology. 2006;15:1159-69.

3. Pettersson A, Graff RE, Ursin G, Santos Silva ID, McCormack V, Baglietto L, et al. Mammographic density phenotypes and risk of breast cancer: a metaanalysis. J Natl Cancer Inst. 2014;106

4. Huo CW, Chew GL, Britt KL, Ingman WV, Henderson MA, Hopper JL, et al. Mammographic density-a review on the current understanding of its association with breast cancer. Breast Cancer Res Treat. 2014;144:479-502.

5. Price ER, Hargreaves J, Lipson JA, Sickles EA, Brenner RJ, Lindfors KK, et al. The California breast density information group: a collaborative response to the issues of breast density, breast cancer risk, and breast density notification legislation. Radiology. 2013;269:887-92

6. Krishnan K, Baglietto L, Apicella C, Stone J, Southey MC, English DR, et al. Mammographic density and risk of breast cancer by mode of detection and tumor size: a case-control study. Breast cancer research: BCR. 2016;18:63.

7. Sartor H, Borgquist S, Hartman L, Zackrisson S. Do pathological parameters differ with regard to breast density and mode of detection in breast cancer? The Malmo diet and cancer study. Breast (Edinburgh, Scotland). 2015;24:12-7.

8. Sartor H, Zackrisson S, Elebro K, Hartman L, Borgquist S. Mammographic density in relation to tumor biomarkers, molecular subtypes, and mode of detection in breast cancer. Cancer causes \& control: CCC. 2015;26:931-9.

9. Ding J, Warren R, Girling A, Thompson D, Easton D. Mammographic density, estrogen receptor status and other breast cancer tumor characteristics. Breast J. 2010;16:279-89.

10. Aiello EJ, Buist DS, White E, Porter PL. Association between mammographic breast density and breast cancer tumor characteristics. Cancer epidemiology, biomarkers \& prevention: a publication of the American Association for Cancer Research, cosponsored by the American Society of Preventive Oncology. 2005;14:662-8.

11. Baglietto L, Krishnan K, Stone J, Apicella C, Southey MC, English DR, et al. Associations of mammographic dense and nondense areas and body mass index with risk of breast cancer. Am J Epidemiol. 2014;179:475-83.

12. Giles GG, English DR. The Melbourne collaborative cohort study. IARC Sci Publ. 2002:156:69-70.

13. Baglietto L, Severi G, English DR, Krishnan K, Hopper JL, McLean C, et al. Circulating steroid hormone levels and risk of breast cancer for postmenopausal women. Cancer epidemiology, biomarkers \& prevention: a publication of the American Association for Cancer Research, cosponsored by the American Society of Preventive Oncology. 2010;19:492-502.

14. Hopper JL. Odds per adjusted standard deviation: comparing strengths of associations for risk factors measured on different scales and across diseases and populations. Am J Epidemiol. 2015;182:863-7.

15. Nguyen $T L$, Aung $Y K$, Evans CF, Yoon-Ho C, Jenkins MA, Sung J, et al. Mammographic density defined by higher than conventional brightness threshold better predicts breast cancer risk for full-field digital mammograms. Breast Cancer Res. 2015;17:142.

16. Kim BK, Choi YH, Nguyen TL, Nam SJ, Lee JE, Hopper JL, et al. Mammographic density and risk of breast cancer in Korean women. Eur J Cancer Prev. 2015:24:422-9.

17. Pepe $\mathrm{M}$, Longton $\mathrm{G}$, Janes $\mathrm{H}$. Estimation and comparison of receiver operating characteristic curves. Stata J. 2009:9:1.

18. Bertrand KA, Scott CG, Tamimi RM, Jensen MR, Pankratz VS, Norman AD, et al. Dense and nondense mammographic area and risk of breast cancer by age and tumor characteristics. Cancer epidemiology, biomarkers \& prevention: a publication of the American Association for Cancer Research, cosponsored by the American Society of Preventive Oncology. 2015;24:798-809.

19. Antoni S, Sasco AJ, dos Santos Silva I, McCormack V. Is mammographic density differentially associated with breast cancer according to receptor status? A meta-analysis. Breast Cancer Res Treat. 2013;137:337-47.

20. Houssami N, Irwig L, Ciatto S. Radiological surveillance of interval breast cancers in screening programmes. The lancet oncology. 2006;7:259-65.
21. Kaviani A, Neishaboury M, Mohammadzadeh N, Ansari-Damavandi M, Jamei K. Effects of obesity on presentation of breast cancer, lymph node metastasis and patient survival: a retrospective review. Asian Pacific journal of cancer prevention: APJCP. 2013:14:2225-9.

22. Chen FY, HY O, Wang SM, YH W, Yan GJ, Tang LL. Associations between body mass index and molecular subtypes as well as other clinical characteristics of breast cancer in Chinese women. Ther Clin Risk Manag. 2013;9:131-7.

23. Keskin O, Aksoy S, Babacan T, Sarici F, Kertmen N, Solak M, et al. Impact of the obesity on lymph node status in operable breast cancer patients. Journal of BUON: official journal of the Balkan Union of Oncology. 2013;18:824-30.

24. Domingo L, Salas D, Zubizarreta R, Bare M, Sarriugarte G, Barata T, et al. Tumor phenotype and breast density in distinct categories of interval cancer: results of population-based mammography screening in Spain. Breast cancer research: BCR. 2014;16:R3

25. Holm J, Humphreys K, Li J, Ploner A, Cheddad A, Eriksson M, et al. Risk factors and tumor characteristics of interval cancers by mammographic density. J Clin Oncol Off J Am Soc Clin Oncol. 2015; https://doi.org/10.1200/ jco.2014.58.9986

26. World Cancer Research Fund/American Institute of Cancer Research. Continuous update project report summary. Food, nutrition, physical activity, and the prevention of breast cancer. 2010;

\section{Submit your next manuscript to BioMed Central and we will help you at every step:}

- We accept pre-submission inquiries

- Our selector tool helps you to find the most relevant journal

- We provide round the clock customer support

- Convenient online submission

- Thorough peer review

- Inclusion in PubMed and all major indexing services

- Maximum visibility for your research

Submit your manuscript at www.biomedcentral.com/submit
Biomed Central 